\title{
Bioactive Phenylenediamine Derivatives of Dehydroacetic Acid: Synthesis, Structural Characterization and Deuterium Isotope Effects ${ }^{\dagger}$
}

\author{
Tomislav Jednačak, ${ }^{a}$ Predrag Novak, ${ }^{\text {a,* }}$ Krunoslav Užarević, ${ }^{a}$ Igor Bratoš, ${ }^{\mathbf{b}}$ \\ Jelena Marković, ${ }^{\mathrm{a}}$ and Marina Cindrić ${ }^{\mathrm{a}}$ \\ ${ }^{a}$ Department of Chemistry, Faculty of Natural Science, University of Zagreb, \\ Horvatovac 102a, HR-10000 Zagreb, Croatia \\ ${ }^{\mathrm{b}}$ PLIVA Croatia Ltd., TAPI Research \& Development, Prilaz baruna Filipovića 25, HR-10000 Zagreb, Croatia
}

\begin{abstract}
Several phenylenediamine derivatives of dehydroacetic acid, 3-acetyl-4-hydroxy-6-methyl- $2 \mathrm{H}$ pyran-2-one have been synthesized and their structure elucidated by using NMR and IR spectroscopies and mass spectrometry. Spectral analyses have pointed toward the localized keto-amine form as the predominant tautomeric form in solution and solid-state which was in agreement with X-ray data. The relatively broad $\mathrm{N}-\mathrm{H}$ stretching bands observed in IR spectra and significant $\mathrm{N}-\mathrm{H}$ proton down-field and keto $\mathrm{C}=\mathrm{O}$ up-field shifts in NMR spectra indicated the presence of intra-molecular hydrogen bonds in all studied compounds. In order to gain further insights into nature of these interactions in solution deuterated isotopomers have been prepared and deuterium isotope effects in ${ }^{13} \mathrm{C}$ NMR spectra have been determined and analyzed. The magnitude and sign of isotope effects have confirmed the existence of intra-molecular hydrogen bonds. Observed differences in isotope effects reflected different hydrogen bond structure and dynamics in studied compounds. The results presented in this paper might help in better understanding of biological properties of the related compounds.(doi: $10.5562 / \mathrm{cca} 1825)$
\end{abstract}

Keywords: dehydroacetic acid, phenylenediamine derivatives, IR, NMR, MS, hydrogen Bonds, tautomerism, deuterium isotope effects

\section{INTRODUCTION}

Dehydroacetic acid, 3-acetyl-4-hydroxy-6-methyl-2Hpyran-2-one possesses interesting biological properties such as fungicide and antibacterial activities and it can also act as a complexing ligand. ${ }^{1,2}$ Furthermore, this compound has several reactive functional groups and can serve as a reagent in organic synthesis. ${ }^{3-6}$ Schiff bases derived from dehydroacetic acid and phenylenediamines have a great potential as bioactive compounds, too. Chelate complexes with Schiff base ligands have found applications in antibacterial therapy based on selective DNA cleveage ability, ${ }^{7}$ brain imaging $^{8}$ and catalysis. ${ }^{9}$ They were also reported to be used in polymerization reactions, as biosensor and as chelating ligands for coordination of transition metal cations. ${ }^{10,11}$

In this paper we report on preparation of ortho (1)-, meta (2)- and para (3)- $N, N^{\prime}$-phenylene-diylbis[3-(1-aminoethyl)-6-methyl-2H-pyran-2,4(3H)-diones] (Figure 1) and their deuterated isotopomers (4-6) in order to study possible hydrogen bonding interactions and tautomeric keto-enol equilibria these compounds might undergo which in turn could affect their biological properties.

Generally, enaminones might exist in two tautomeric forms: keto-amine and enol-imine (Figure 2). ${ }^{12}$ They have conjugated $\mathrm{N}-\mathrm{C}=\mathrm{C}-\mathrm{C}=\mathrm{O}$ moiety with two electron-deficient centers at atoms $\mathrm{C}-1$ and $\mathrm{C}-3$, electron rich atom $\mathrm{C}-2$ and an amino/imino group. Hence, they may act as both electrophiles and nucleophiles. A strong intramolecular resonance assisted hydrogen bond (RAHB) was found to be present in both tautomeric forms (Figure 2). ${ }^{13,14}$

Hydrogen bonding is one of the major factors that govern the overall structure and functionality of biologically important molecules. ${ }^{15}$ Hydrogen bonds in solution can successfully be studied by the combination of various spectroscopic and theoretical methods. ${ }^{16-18}$ Furthermore, $\mathrm{X}$-ray structural analysis proved the existence of ketoamine tautomeric form and intramolecular hydrogen bonds in $\mathbf{1}$ in solid state. ${ }^{5}$ The same tautomer was ob-

\footnotetext{
$\dagger$ This article belongs to the Special Issue Chemistry of Living Systems devoted to the intersection of chemistry with life.

* Author to whom correspondence should be addressed. (E-mail: pnovak@chem.pmf.hr)
} 


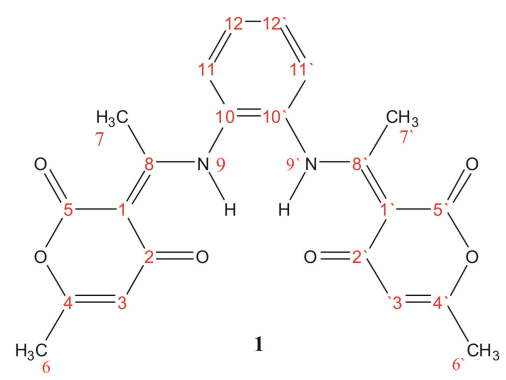

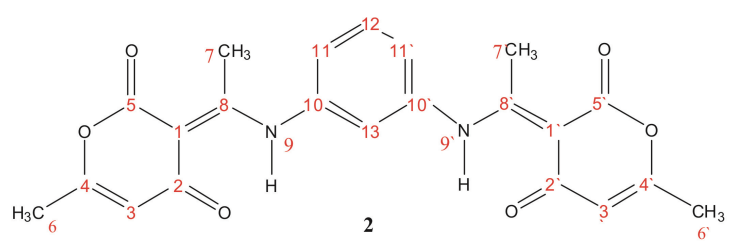

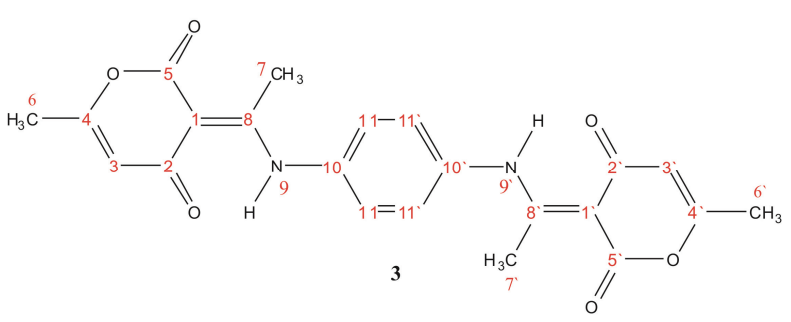

Figure 1. The structures and atom numbering of 1-3.

served in the asymmetrical Schiff bases derived from dehydroacetic acid and $p$-phenylenediamine. ${ }^{19}$ Since the position of tautomeric equilibria can be crucial for reactivity of these compounds, one of the most important aims of this work was to study solvent influence on tautomeric equilibria and nature of hydrogen bonds in 1-3.

Isotope effects have proven useful to study tautomerism and hydrogen bonds in solution. ${ }^{20-27}$ Many isotopes have been investigated, but the most important is deuterium owing to the largest change in mass upon proton/deuterium substitution. Secondary deuterium isotope effects in ${ }^{13} \mathrm{C}$ NMR spectra (DIE) can be determined as the difference in chemical shifts between carbon substituted with hydrogen $\delta^{13} \mathrm{C}(\mathrm{H})$ and carbon substituted with deuterium $\delta^{13} \mathrm{C}(\mathrm{D})$, where $n$ represents a<smiles>[R]C1=CC([R])N([R])C=C1[R]</smiles>

(a)

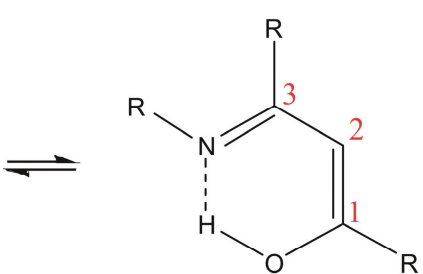

(b)
Figure 2. Tautomeric structures of enaminones: a) ketoamine, b) enol-imine.

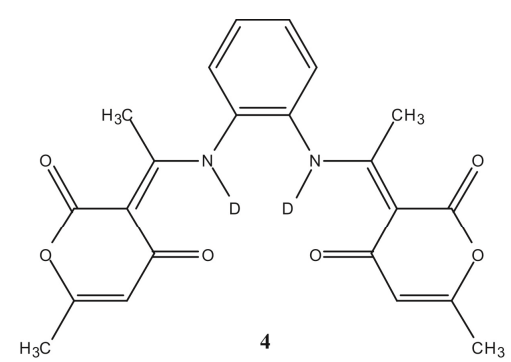<smiles>[2H]N(C(C)=C1C(=O)C=C(C)OC1=O)c1cccc(N([2H])C(C)=C2C(=O)C=C(C)OC2=O)c1</smiles>

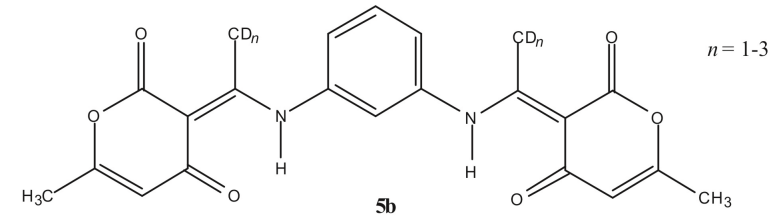

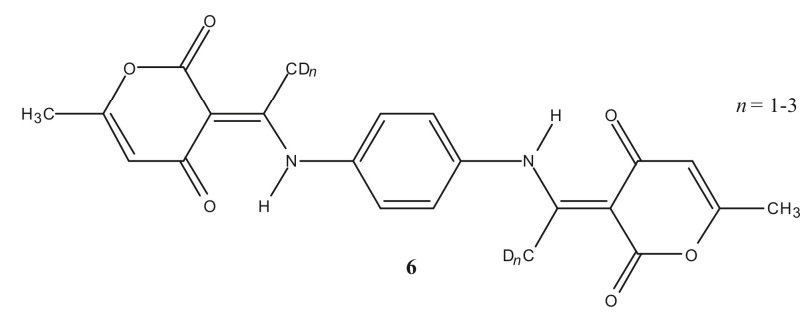

Figure 3. Deuterated isotopomers of dehydroacetic acid derivatives.

number of bonds between the investigated nucleus and deuterium:

$$
{ }^{n} \Delta^{13} \mathrm{C}(\mathrm{D})=\delta^{13} \mathrm{C}(\mathrm{H})-\delta^{13} \mathrm{C}(\mathrm{D})
$$

DIE can be intrinsic and equilibrium in origin. They differ in magnitude, sign and temperature dependence. Intrinsic isotope effects can be observed in systems which are not in chemical equilibrium and they are described with a potential energy curve with one minimum. Equilibrium isotope effects, which are described with a two-minimum potential energy curve, exist when isotope exchange alters chemical equilibrium. ${ }^{13,27}$ The measured deuterium isotope effects can help in elucidating the reactivity of certain functional groups in studied compounds, the nature and strength of possible hydrogen bonds and influence of the solvent. Hence, we prepared deuterated isotopomers 4-6 (Figure 3) and recorded their ${ }^{13} \mathrm{C}$ NMR spectra. An attention was also paid to conditions of deuteration which might occur at different sites in the molecule yielding various isotopomers. 


\section{EXPERIMENTAL}

\section{Materials}

Dehydroacetic acid, ortho-, meta- and para- phenylenediamine, methanol- $\mathrm{d}_{4}$, chloroform- $\mathrm{d}_{1}$ and deuterium oxide were purchased from commercial sources and used without further purification. Chloroform and dichloromethane were dried using $\mathrm{P}_{2} \mathrm{O}_{5}$. Methanol was dried using iodine and magnesium turnings and then distilled.

\section{Synthesis of Non-deuterated Compounds}

Ortho- $N, N^{\prime}$-phenylene-diylbis[3-(1-aminoethyl)-6-methyl-2H-pyran-2,4(3H)-dione] (1) was prepared as published in the literature. ${ }^{5} 2.5 \mathrm{mmol}$ of orthophenylenediamine was added in a hot methanolic solution $(15 \mathrm{ml})$ of dehydroacetic acid $(5.0 \mathrm{mmol})$. The reaction mixture was refluxed and temporally stirred for $10 \mathrm{~h}$. After staying for 6 days at approximately $4{ }^{\circ} \mathrm{C}$ crystals were filtered, rinsed with cold ethanol and dried under vacuo. Yield: $0.53 \mathrm{~g}, 52 \%$.

Meta- $N, N^{\prime}$-phenylene-diylbis[3-(1-aminoethyl)-6methyl-2H-pyran-2,4(3H)-dione] (2) was prepared by a similar procedure. Solution of meta-phenylenediamine $(0.27 \mathrm{mmol}$ in $5 \mathrm{ml})$ was added in a hot methanolic solution $(6 \mathrm{ml})$ of dehydroacetic acid $(0.13 \mathrm{mmol})$. The reaction mixture was refluxed and temporally stirred for $4 \mathrm{~h}$. After staying for one day at room temperature, crystals were filtered, rinsed with cold methanol and dried on the air. Yield: $35.3 \mathrm{mg}, 65 \%$.

Para- $N, N^{\prime}$-phenylene-diylbis[3-(1-aminoethyl)-6methyl-2H-pyran-2,4(3H)-dione] (3) was prepared in a hot methanolic solution $(6 \mathrm{ml})$ of deydroacetic acid $(2.85 \mathrm{mmol})$ with addition of para-phenylenediamine ( $0.71 \mathrm{mmol}$ in $4 \mathrm{ml}$ of methanol). The reaction mixture was refluxed and temporally stirred for $6 \mathrm{~h}$. After staying for approximately 2 days, crystals were filtered, rinsed with cold methanol and dried on the air. Yield: $20.7 \mathrm{mg}, 71.4 \%$.

\section{Synthesis of Deuterated Isotopomers}

Partially deuterated isotopomer of (1) was prepared by dissolving $1(30 \mathrm{mg})$ in deuterated methanol $(1.0 \mathrm{ml})$ and by adding a few drops of deuterium oxide. The solution was refluxed for $3 \mathrm{~h}$, evaporated under vacuo to $1 / 3$ of initial volume and the reaction product was rinsed and dried. Yield: $21.5 \mathrm{mg}, 71 \%$.

Partially deuterated isotopomer of (2) was prepared by dissolving $2(15 \mathrm{mg})$ in deuterated methanol $(1.0 \mathrm{ml})$ and by adding a few drops of deuterium oxide. Solvent was almost completely evaporated under vacuo and the reaction product at the bottom of the reaction flask was rinsed and dried. Yield: $10.5 \mathrm{mg}, 70 \%$.

Partially deuterated isotopomer of (2) was also prepared by dissolving $2(15 \mathrm{mg})$ in the metha- nol/chloroform mixture $(v: v=2: 1,2.0 \mathrm{ml})$ and by adding a few drops of deuterium oxide. The solution was refluxed for $5 \mathrm{~h}$, evaporated under vacuo to $1 / 3$ of initial volume and the reaction product was rinsed and dried. Yield: $11 \mathrm{mg}, 73.3 \%$.

Partially deuterated isotopomer of (3), owing to its low solubility in methanol, was prepared by dissolving $3(10 \mathrm{mg})$ in solution of deuterated methanol and chloroform $(v: v=2: 1,2.0 \mathrm{ml})$ by adding a few drops of deuterium oxide. The solution was refluxed for $5 \mathrm{~h}$ and then evaporated under vacuo to $1 / 3$ of the initial volume. Crystals were filtered and dried. Yield: $11 \mathrm{mg}$, $66.7 \%$.

To the best of our knowledge, the synthesis of compounds 2-6 has not yet been reported in the literature.

\section{IR Spectroscopy}

IR spectra of compounds 1-3 and deuterated isotopomers 4-6 were recorded on Perkin-Elmer Spectrophotometer 502, with a resolution of $2 \mathrm{~cm}^{-1}$ and 4 scans per spectrum. Samples were prepared by $\mathrm{KBr}$ pellets.

\section{Mass spectrometry}

Mass spectra were recorded on a Waters Micromass QTOF micro instrument equipped with an electrospray ionization (ESI) source and operating in positive ion mode. The instrument parameters were as follows: capillary voltage $3.0 \mathrm{kV}$, sample cone voltage $18 \mathrm{~V}$, extractor voltage $1 \mathrm{~V}$, source temperature $100^{\circ} \mathrm{C}$, desolvation temperature $150{ }^{\circ} \mathrm{C}$ and desolvation gas flow 350 $\mathrm{L} / \mathrm{h}$.

Samples were dissolved either in a 1:1 $(v: v)$ mixture of acetonitrile and water or in methanol, to a concentration of about $10 \mu \mathrm{g} / \mathrm{mL}$ and introduced into the ESI source from a gastight $250 \mu \mathrm{L}$ syringe driven by a syringe pump at a flowrate of $10 \mu \mathrm{L} / \mathrm{min}$.

\section{NMR spectroscopy}

One-dimensional $\left({ }^{1} \mathrm{H}\right.$ and APT) and two-dimensional (COSY, HSQC and HMBC) NMR spectra were recorded on a Bruker Avance 600 spectrometer equipped with an inverse probe and $\mathrm{z}$ - gradient accessories with constant magnetic field operating at $14.2 \mathrm{~T}$. Samples were measured at $298 \mathrm{~K}$ in $5 \mathrm{~mm}$ tubes. $\mathrm{CDCl}_{3}$ was used as solvent and TMS as internal standard.

Proton spectra with spectral width of 12019.23 $\mathrm{Hz}$, acquisition time of $1.36 \mathrm{~s}$ and digital resolution of $0.55 \mathrm{~Hz}$ per point were measured with 32 scans. A number of points in time domain was $32 \mathrm{~K}$.

APT spectra with spectral width of $35971.22 \mathrm{~Hz}$, acquisition time of $0.91 \mathrm{~s}$ and digital resolution of 0.55 $\mathrm{Hz}$ per point were measured with 51791 scans per spectrum. Number of points in time domain was $64 \mathrm{~K}$. 
Table 1. Characteristic IR vibrational modes $\left(\mathrm{cm}^{-1}\right)$ of $\mathbf{1}-\mathbf{3}$

\begin{tabular}{lccc}
\hline Vibrational mode & \multicolumn{1}{c}{} & $\tilde{\boldsymbol{v}} / \mathrm{cm}^{-1}$ & $\mathbf{3}$ \\
\hline$v(\mathrm{~N}-\mathrm{H})$ & $\mathbf{1}$ & $\mathbf{2}$ & 3459 \\
$v(\mathrm{C}-\mathrm{H})_{\text {aromatic }}$ & 3450 & 3400 & - \\
$v(\mathrm{C}-\mathrm{H})_{\text {aliphatic }}$ & 3050 & 3050 & 2950 \\
$v(\mathrm{C}=\mathrm{O})_{\text {lactone }}$ & 2950 & 2950 & 1700 \\
$v(\mathrm{C}=\mathrm{O})_{\text {ketone }}$ & 1706 & 1708 & 1559 \\
$v(\mathrm{C}-\mathrm{H})_{\text {o.o.p.* bending, aromatic }}$ & 1570 & 1563 & 800 \\
\hline
\end{tabular}

* out of plane

In the gCOSY experiment, 2048 points in F2 dimension and 512 increments in F1 dimension were used. Spectra were measured with spectral width of 12019.23 Hz, 4 pulses per increment and relaxation delay of $1 \mathrm{~s}$. Digital resolution was $5.87 \mathrm{~Hz}$ per point in $\mathrm{F} 2$ and $23.44 \mathrm{~Hz}$ per point in $\mathrm{F} 1$ dimension.

For gHSQC and gHMBC spectra 2048 points in F2 dimension and 512 increments in F1 dimension were used. Spectral width was $12019 \mathrm{~Hz}$ in F2 dimension and $36216 \mathrm{~Hz}$ in F1 dimension. Relaxation delay was $1 \mathrm{~s}$ and number of scans was 128. Digital resolution was 5.87 and $141.48 \mathrm{~Hz}$ per point in F2 and F1 dimension, respectively. A delay for long-range coupling was set to $65 \mathrm{~ms}$.

\section{RESULTS AND DISCUSSION}

\section{Structural Characterization}

The structures of prepared compounds 1-3 were characterized by IR and NMR spectroscopies and MS spec- trometry. IR spectra revealed characteristic vibrational modes of phenylenediamines and diones. These are displayed in Table 1.

Owing to structural similarity, the IR spectra of 1-3 are very similar in the range $3500-1100 \mathrm{~cm}^{-1}$. The $\mathrm{C}-\mathrm{H}$ aromatic stretching vibration in $\mathbf{3}$ is partially overlapped by a broad $\mathrm{N}-\mathrm{H}$ stretching vibration band and hence could not be unambiguously assigned in the spectrum. Differences in out of plane bending vibrations are due to different substitution at the benzene ring. The broadening of secondary amine $\mathrm{N}-\mathrm{H}$ stretching vibration band at $\approx 3450 \mathrm{~cm}^{-1}$ pointed towards the presence of intramolecular hydrogen bonds. This is in agreement with the results obtained by X-ray diffraction analysis of 1. ${ }^{5}$ The existence of $\mathrm{C}=\mathrm{O}$ stretching band of conjugated ketone and lack of $\mathrm{O}-\mathrm{H}$ stretching mode in $\mathbf{1}-\mathbf{3}$ indicated that the predominant form in solid state is the keto-amine.

The ESI mass spectra of 1-3 showed the existence of precursor ion $[\mathrm{M}+\mathrm{H}]^{+}$at $m / z=409$ and the expected

Table 2. ${ }^{1} \mathrm{H}$ and ${ }^{13} \mathrm{C}$ NMR chemical shifts (ppm) for $\mathbf{1}-\mathbf{3}$ in $\mathrm{CDCl}_{3}$

\begin{tabular}{|c|c|c|c|c|c|c|}
\hline \multirow{2}{*}{ Atom } & \multicolumn{2}{|c|}{1} & \multicolumn{2}{|c|}{2} & \multicolumn{2}{|c|}{3} \\
\hline & ${ }^{1} \mathrm{H} \delta / \mathrm{ppm}$ & ${ }^{13} \mathrm{C} \delta / \mathrm{ppm}$ & ${ }^{1} \mathrm{H} \delta / \mathrm{ppm}$ & ${ }^{13} \mathrm{C} \delta / \mathrm{ppm}$ & ${ }^{1} \mathrm{H} \delta / \mathrm{ppm}$ & ${ }^{13} \mathrm{C} \delta / \mathrm{ppm}$ \\
\hline $1\left(1^{\prime}\right)$ & & 97.42 & & 97.19 & & 97.28 \\
\hline $2\left(2^{\prime}\right)$ & & 184.51 & & 184.53 & & 184.57 \\
\hline $3\left(3^{\prime}\right)$ & 5.73 & 106.39 & 5.77 & 106.46 & 5.79 & 106.54 \\
\hline $4\left(4^{\prime}\right)$ & & 163.22 & & 163.42 & & 163.40 \\
\hline $5\left(5^{\prime}\right)$ & & 162.46 & & 162.59 & & 162.72 \\
\hline $6\left(6^{\prime}\right)$ & 2.16 & 19.83 & 2.18 & 19.47 & 2.20 & 19.72 \\
\hline $7\left(7^{\prime}\right)$ & 2.55 & 19.94 & 2.63 & 19.85 & 2.66 & 19.89 \\
\hline $8\left(8^{\prime}\right)$ & & 175.65 & & 174.89 & & 174.82 \\
\hline $9\left(9^{\prime}\right)$ & 16.12 & & 16.07 & & 16.04 & \\
\hline $10\left(10^{\circ}\right)$ & & 132.19 & & 137.32 & & 135.56 \\
\hline $11\left(11^{\prime}\right)$ & 7.49 & 128.60 & 7.24 & 124.65 & 7.29 & 126.27 \\
\hline $12\left(12^{\prime}\right)$ & 7.31 & 127.09 & 7.57 & 130.31 & & \\
\hline $13\left(13^{`}\right)$ & & & 7.07 & 122.36 & & \\
\hline
\end{tabular}




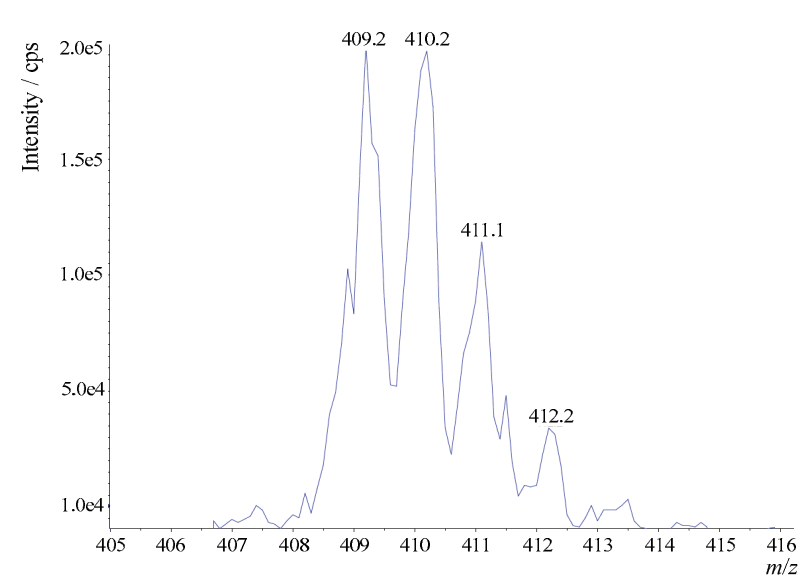

Figure 4. Precursor ion peaks in the mass spectrum of 6.

fragmentation pattern. The precursor ion signal at $\mathrm{m} / \mathrm{z}=$ 411 in the mass spectra of deuterated compounds 1 (isotopomer 4) and $\mathbf{2}$ (isotopomer 5a) obtained in methanol indicated the exchange of both $\mathrm{N}-\mathrm{H}$ groups with deuterium. Surprisingly, precursor ion peaks of deuterated compounds $\mathbf{5 b}$ and $\mathbf{6}$ prepared in a mixture of deuterated methanol and chloroform pointed towards multiple deuteration. This finding will be discussed later on.

The analysis of ${ }^{1} \mathrm{H}$ and ${ }^{13} \mathrm{C}$ NMR spectra confirmed the structures of $\mathbf{1}-\mathbf{3}$ in solution and corroborated the presence of the keto-amine form (Table 2). The chemical shifts of $\mathrm{C}-2\left(2^{\prime}\right)$ atoms assigned at $\approx 184.5$ ppm corresponded to the keto group of dehydroacetic acid involved in the RAHB. The amino group has been found in proton spectrum at $16.1 \mathrm{ppm}$. Proton chemical shifts at $\approx 2.2 \mathrm{ppm}$ and $\approx 2.6 \mathrm{ppm}$ were observed for methyl protons $\mathrm{H}-6\left(6^{\prime}\right)$ and $\mathrm{H}-7\left(7^{\prime}\right)$, respectively. The COSY spectra of 1-3 exhibited correlation peaks corresponding to different substitutions at the benzene ring. Two correlated aromatic proton signals between $\mathrm{H}$ $11\left(11^{\prime}\right)$ and $\mathrm{H}-12\left(12^{\prime}\right)$ with equal integrals revealed ortho- substitution in 1 . The $\mathrm{H}-13\left(13^{\prime}\right)$ proton singlet at $7.07 \mathrm{ppm}$ confirmed the meta- substitution in 2 . The absence of correlation peaks between aromatic protons in COSY spectrum of $\mathbf{3}$ indicated the symmetric parasubstitution at the benzene ring.

The HMBC spectra of $\mathbf{1}-\mathbf{3}$ exhibited correlation peaks between C-4(4') and H-6(6') as well as between C-8(8') and H-7(7'). Significant line-broadening and deshielding effects observed for amine $\mathrm{N}-\mathrm{H}$ protons and shielding of keto $\mathrm{C}-2\left(2^{\prime}\right)$ carbons reflected interactions of these groups via intramolecular hydrogen bonds.

\section{Deuterium Isotope Effects}

Deuterium isotope effects have found practical applications as a structural tool for analysis of hydrogen bonds and tautomeric equilibria in solution. ${ }^{15,20}$ In order to

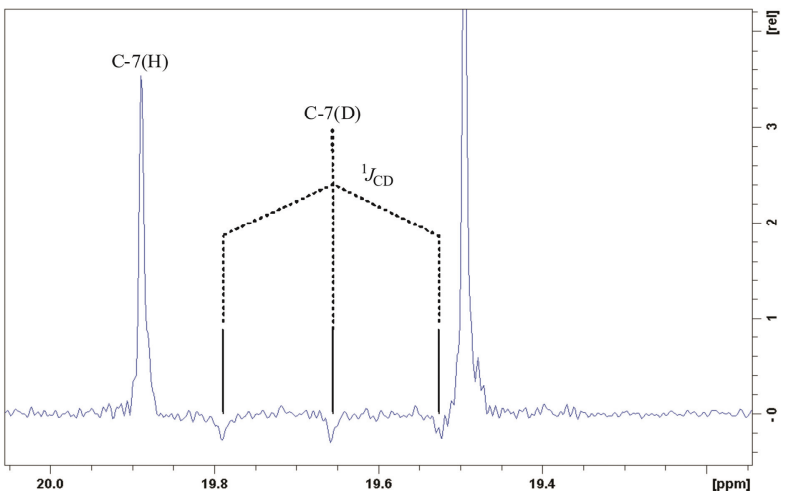

Figure 5. The methyl region of ${ }^{13} \mathrm{C}$ NMR APT spectrum of 6 .

elucidate structure and dynamics of possible hydrogen bonds and influence of the non-polar solvent we prepared deuterated isotopomers of $\mathbf{1}-\mathbf{3}$ in solution of deuterated methanol. According to NMR and MS spectra, deuteration of $\mathrm{N}-\mathrm{H}$ group was successful for $\mathbf{1}$ and $\mathbf{2}$ giving isotopomers 4 and 5a (Figure 3).

An attempt to prepare deuterated compound $\mathbf{3}$ (isotopomer 6) in deuterated methanol was unsuccessful due to its very low solubility. Hence, isotopomer 6 was prepared in a mixture of deuterated methanol and chloroform (Figure 3). Deuteration of $\mathbf{2}$ was also performed under these conditions yielding isotopomer $\mathbf{5 b}$ (Figure 3 ).

${ }^{1} \mathrm{H}$ NMR and mass spectra of isotopomers 4 and 5 a revealed that the deuteration occurred at both amino groups. Furthermore, in mass spectra of isotopomers $\mathbf{5 b}$ and 6 precursor ion peaks at $\mathrm{m} / \mathrm{z}=409.2,410.2,411.1$ and 412.2 were observed (Figure 4). These findings pointed towards the formation of multiple deuterated species. The percentage of particular species can be estimated from the peak intensities. Peaks at $\mathrm{m} / \mathrm{z} 411.1$ and 412.2 corresponded to three and four deuterium atoms in the molecule which could not be obtained only by deuteration of amino groups. This issue was resolved by a close inspection of ${ }^{13} \mathrm{C}$ NMR spectra.

Namely, the ${ }^{13} \mathrm{C}$ NMR spectra of deuterated compounds $5 \mathbf{b}$ and $\mathbf{6}$ prepared in a mixture of deuterated methanol and chloroform exhibited C-D triplets around $19.7 \mathrm{ppm}$ indicating the presence of monodeuterated methyl groups in $\alpha$-position to amino group (Figure 5). The ${ }^{13} \mathrm{C}$ NMR spectra recorded with more scans revealed quintets and septets corresponding to two and three deuteriums in the methyl groups, respectively. According to these findings, the following mechanism of deuteration shown in Figure 6 can be proposed.

The mechanism involves hyperconjugation of polar resonant form (c) and the deuteration of methyl groups. The resonant form (c) is stabilized by the partial double bond character of $\mathrm{C}-\mathrm{N}$ bond, present both in amides and their higher homologues enaminones. The catalytic $\mathrm{D}^{+}$ions might come from the dissociation of $\mathrm{CD}_{3} \mathrm{OD}$ or as a consequence of the decomposition of 


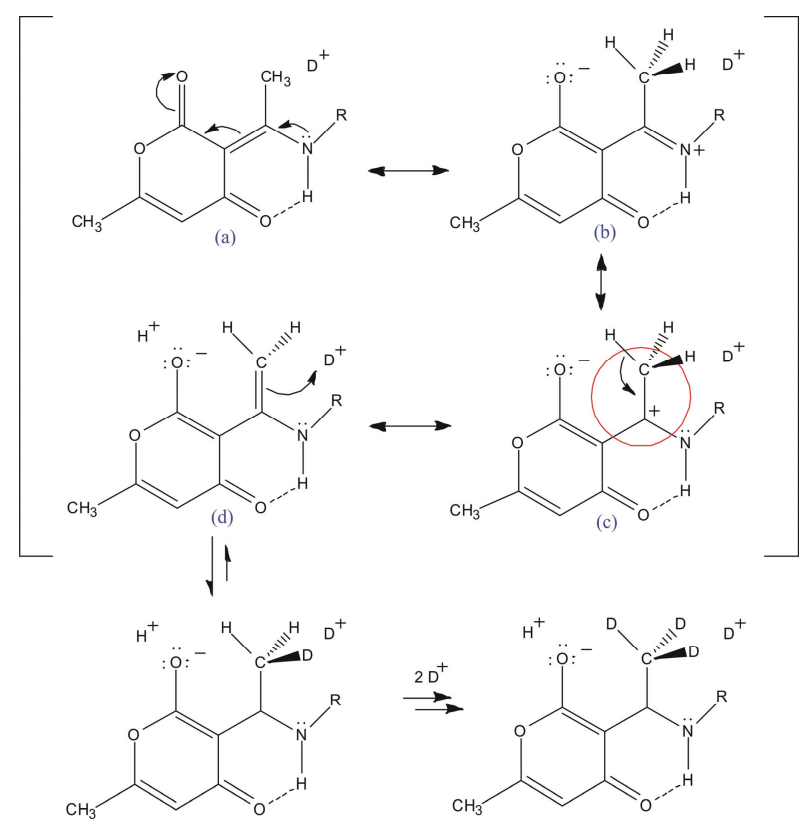

Figure 6. The mechanism of the methyl group deuteration at position 7 .

$\mathrm{CDCl}_{3}$ yielding $\mathrm{D}^{+}$and $\mathrm{CCl}_{3}{ }^{-}$which can be accelerated by heating. ${ }^{28}$

Owing to the higher $\mathrm{p} K_{\mathrm{a}}$ value of the mixture of deuterated methanol and chloroform in comparison with the pure deuterated methanol, the deuteration of $\mathrm{N}-\mathrm{H}$ groups is less possible and the main reaction products are $\mathbf{5 b}$ and $\mathbf{6}$. This is in accordance with much smaller deuterium isotope effects measured for these compounds in comparison with $\mathbf{4}$ and $\mathbf{5 a}$ as seen in Table 3.

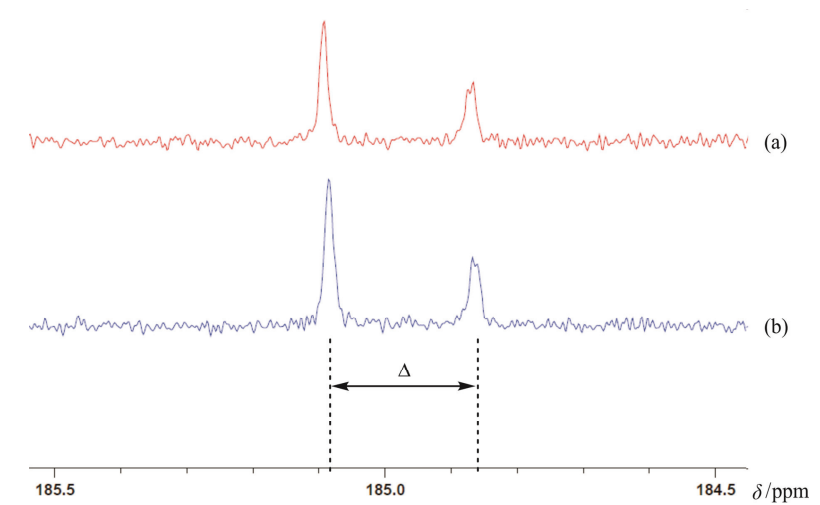

Figure 7. Determination of a deuterium isotope effect at C$2\left(2^{\prime}\right)$ in 5a. The narrow region APT spectrum of the partially deuterated 5a (a) before and (b) after addition of the nondeuterated isotopomer.

Hence, the site and selectivity of deuteration depend on solvent properties and reaction conditions.

Subsequently, DIEs were determined from mixtures of partially deuterated 4-6 and non-deuterated 13 samples using the equation (1). The sign of DIE was determined by quantitative addition of the nondeuterated sample in the NMR tube of the deuterated sample, as demonstrated in Figure 7. DIEs are given in Table 3.

In 4 and 5 a generally high values of DIE were observed. The high positive values at $\mathrm{C}-8\left(8^{\circ}\right)$ in $\mathbf{4}(+320.9$ $\mathrm{ppb})$ and $\mathbf{5 a}(+250.0 \mathrm{ppb})$ provided further evidence for the localized keto-amine form in solution stabilized by intra-molecular $\mathrm{N}-\mathrm{H} \cdots \mathrm{O}$ hydrogen bonds. Relatively

Table 3. Deuterium isotope effects (ppb) on ${ }^{13} \mathrm{C}$ NMR chemical shifts for $\mathbf{4}-\mathbf{6}$ in $\mathrm{CDCl}_{3}$

\begin{tabular}{|c|c|c|c|c|}
\hline \multirow{2}{*}{ Atom } & \multicolumn{4}{|c|}{${ }^{n} \Delta^{13} \mathrm{C}(\mathrm{D}) / \mathrm{ppb}$} \\
\hline & 4 & $5 a$ & $5 \mathbf{b}^{(\mathrm{a})}$ & $6^{(\mathrm{a})}$ \\
\hline $1\left(1^{\prime}\right)$ & (b) & 600.0 & -7.7 & -8.0 \\
\hline $2\left(2^{\prime}\right)$ & (b) & 700.0 & & -7.8 \\
\hline $3\left(3^{\prime}\right)$ & -193.1 & -187.5 & & \\
\hline $4\left(4^{\prime}\right)$ & 100.1 & 375.0 & & \\
\hline $5\left(5^{\prime}\right)$ & 108.0 & -150.0 & & -9.4 \\
\hline $6\left(6^{\prime}\right)$ & (b) & 100.0 & & \\
\hline $7\left(7^{\prime}\right)$ & (b) & -350.0 & 231.2 & 230.7 \\
\hline $8\left(8^{\prime}\right)$ & 320.9 & 250.0 & 22.9 & 24.1 \\
\hline $9\left(9^{\prime}\right)$ & & & & \\
\hline $10\left(10^{\prime}\right)$ & (b) & 500.3 & & \\
\hline $11\left(11^{\prime}\right)$ & -132.5 & (b) & 7.7 & 9.2 \\
\hline $12\left(12^{\prime}\right)$ & -107.9 & 500.5 & & \\
\hline $13\left(13^{\prime}\right)$ & & (b) & 7.4 & \\
\hline
\end{tabular}

(a) prepared in a mixture of deuterated methanol and chloroform

(b) broad signal 
high values of DIEs through five bonds observed at C-3(3') and C-4(4') in $\mathbf{4}$ and $\mathbf{5 a}$ as well as that at C$2\left(2^{\prime}\right)$ in $\mathbf{5 a}$ are in accordance with this. The values of DIEs at C-10(10'), C-11(11') and C-12(12') are also a consequence of an efficient transfer of isotopic perturbation through conjugated system and hydrogen bonds. The difference in sign and magnitude of DIEs in $\mathbf{4}$ and 5a could be explained by different structure and dynamics of hydrogen bonds in these molecules. Due to the proximity of keto and amino groups, $\mathrm{N}-\mathrm{H} \cdots \mathrm{O}$ as well as $\mathrm{N}-\mathrm{H} \cdots \mathrm{N}$ intra- and inter-molecular hydrogen bonds between two dehydroacetic acid moieties are possible in 4 as also observed in solid state. ${ }^{5}$ On the other hand, a larger distance between these units in $\mathbf{5 a}$ prevents the formation of the corresponding intramolecular hydrogen bonding interactions.

The magnitude of DIEs in $\mathbf{5 b}$ and $\mathbf{6}$ prepared in solution of methanol and chloroform depends on the number of deuterium atoms in the methyl groups. Hence, in ${ }^{13} \mathrm{C}$ NMR spectra cumulative effects were observed. $^{22,29}$ The highest value of DIE in both compounds was that observed at the site of deuteration, e.g. at $\mathrm{C}-7\left(7^{\prime}\right)$. The triplets arising from a scalar coupling between methyl carbon and directly attached deuterium were observed in ${ }^{13} \mathrm{C}$ NMR spectra (Figure 5). High values of DIE (22.9 and $24.1 \mathrm{ppb}$ ) at atom C-8(8') in $\mathbf{5 b}$ and 6 could be attributed to the proximity of deuterium and are intrinsic in nature. Negative DIEs were observed at carbonyl carbons C-2(2') and C-5(5') in 6 whereas no such effects were detected in $\mathbf{5 b}$. It is not quite clear what the reason for this observation is but inter-molecular interactions with other molecules and influence of the solvent which can easily approach these $\mathrm{C}=\mathrm{O}$ groups cannot be excluded. ${ }^{30}$

Overall values of DIEs in 4-6 are the sum of equilibrium and intrinsic contributions. Generally, equilibrium DIEs have higher magnitude than intrinsic ones. ${ }^{15,20,27}$ Much larger values of DIEs in isotopomers $\mathbf{4}$ and $5 \mathbf{a}$ with respect to those observed in $\mathbf{5 b}$ and $\mathbf{6}$ can be rationalized by an efficient transmission pathway through intramolecular $\mathrm{N}-\mathrm{H}(\mathrm{D}) \cdots \mathrm{O}$ hydrogen bonds.

Acknowledgements. This study was supported by the Ministry of Science, Education and Sports of the Republic of Croatia (Project Nos. 119-1191342-1083 and 119-1191342-1082). We thank Prof. Hrvoj Vančik and Katarina Čuljak for helpful suggestions.

\section{REFERENCES}

1. D. M. Fouad, N. M. Ismail, M. A. El-Gahami, and S. A. Ibrahim, Spectrochim. Acta Part A 67 (2007) 564-567.
2. E. Mikami, T. Goto, T. Ohno, H. Matsumoto, and M. Nishida, J. Pharmaceut. Biomed. Anal. 28 (2002) 261-267.

3. E. Marengo, V. Gianotti, S. Angioi, and M.C. Gennaro, J. Chromatogr. A 1029 (2004) 57-65.

4. M. Z. Chalaca, J. D. Figueroa-Villar, J. A. Ellena, and E. E. Castellano, Inorg. Chim. Acta 328 (2002) 45-52.

5. M. Cindrić, T. K. Novak, and K. Užarević, J. Mol. Struct. $\mathbf{7 5 0}$ (2005) 135-141.

6. O. Prakash, A. Kumar, and S. P. Singh, Heterocycles 63 (2004) 1193-1220.

7. N. Raman, S. Thalamuthu, J. D. Raja, M. A.Neelakandan, and S. Banerjee, J. Chil. Chem. Soc. 53 (2008) 1439-1443.

8. A. M. Verbruggen, Eur. J. Nucl. Med. 17 (1990) 346-364.

9. R. I. Kureshy, N. H. Khan, S. H. R. Abdi, S. T. Patel, P. Iyer, E. Suresh, and P. Dastidar, J. Mol. Catal. A: Chem. 160 (2000) 217-227.

10. I. Roth, A. Aziz Jbarah, R. Holze, M. Friedrich, and S. Spange, Macromol. Rapid Commun. 27 (2006) 193-199.

11. C. Deng, M. Li, Q. Xie, M. Liu, Y. Tan, X. Xu, and S. Yao, Anal. Chim. Acta 557 (2006) 85-94.

12. A. R. Katritzky, I. Ghiviriga, D. C. Oniciu, R. A. More O'Ferrall, and S. M. Walsh J. Chem. Soc., Perkin Trans. 2, (1997) 26052608.

13. G. Gilli, F. Bellucci, V. Ferretti, and V. Bertolasi, J. Am. Chem. Soc. 111 (1989) 1023-1028.

14. S.R. Salman, S.H. Shawkat, and G. M. Al-Obaidi, Can. J. Spectrosc. 35 (1990) 25-27.

15. P. E. Hansen, NMR Studies of Isotope Effects of Compounds with Intramolecular Hydrogen Bonds, in: A. Kohen and H. H. Limbach (Eds.), Isotope Effects in Chemistry and Biology, CRC Press, Taylor \& Francis Group, Boca Raton, 2006, pp. 253-275.

16. P. Novak, V. Gabelica, D. Žiher, D. Kovaček and Z. Ivezić, J. Mol. Struct. 565-566 (2001) 13-16.

17. P. Novak, K. Pičuljan, T. Hrenar, T. Biljan, and Z. Meić, J. Mol. Struct. 919 (2009) 66-71.

18. P. Novak, K. Pičuljan, T. Hrenar, and V. Smrečki, Croat. Chem. Acta 82 (2) (2009) 477-483.

19. K. Užarević, M. Rubčić, V. Stilinović, B. Kaitner, and M. Cindrić, J. Mol. Struct. 984 (2010) 232-239.

20. P. Novak, D. Vikić-Topić, V. Smrečki, and Z Meić, Isotope Effects in NMR spectra as a Structural Tool for Organic Molecules, in: A.-ur Rahman (Ed.), New Advances in Analytical Chemistry, Harwood Academic Publishers, Singapore, 2000, pp. 135-168.

21. P. Novak, K. Pičuljan, T. Biljan, T. Hrenar, M. Cindrić, M. Rubčić, and Z. Meić, Croat. Chem. Acta 80 (3-4) (2007) 575-581.

22. P. Novak, D. Vikić-Topić, Z. Meić, and E. Gacs-Baitz, Magn. Res. Chem. 34 (1996) 610-615.

23. P. Novak, D. Škare, S. Sekušak, and D. Vikić-Topić, Croat. Chem. Acta 73 (4) (2000) 1153-1170.

24. S. Bolvig, P. E. Hansen, D. Wemmer, and P. Williams, J. Mol. Struct. 509 (1999) 171-181.

25. T. Dziembowska, P. E. Hansen, and Z. Rozwadowski, Progr. NMR Spectrosc. 45 (2004) 1-29.

26. Z. Rozwadowski, K. Ambroziak, T. Dziembowska, and M. Kotfica, J. Mol. Struct. 643 (2002) 93-100.

27. P. E. Hansen, Progr. NMR Spectrosc. 20 (1988) 207-255.

28. http://www.isotope.com/uploads/File/NMRUNpriced-proof.pdf

29. V. Smrečki, D. Vikić-Topić, Z. Meić, and P. Novak, Croat. Chem. Acta 69 (1996) 1501-1509.

30. P. Novak, D. Vikić-Topić, Z. Meić, S. Sekušak, and A. Sabljić $J$. Mol. Struct. 356 (1995) 131-141. 